\title{
Interlinkages between Indicators of Sustainable Development Goals: Evidence from Seven Low Income and Lower Middle-Income Countries
}

\author{
Suyu Liu ${ }^{1}$ \\ ${ }^{1}$ Department of Policy Research and Statistics, United Nations Industrial Development Organization (UNIDO), \\ Vienna, Austria \\ Correspondence: Suyu Liu, Vienna, Austria. E-mail: suyu.liu@linacre.ox.ac.uk
}

Received: May 20, 2020 Accepted: June 15, 2020 Online Published: June 19, 2020

\begin{abstract}
In 2015, 17 Sustainable Development Goals (SDGs) were adopted by member states of United Nations as a blueprint to achieve a better and more sustainable future for all. Up to date, the global indicator of framework of SDGs has 247 indicators (including repetitive indicators), which monitor progress of achieving the SDGs. The interlinkages and integration of SDG indicators have attracted attention from scholars and practitioners, however, there is limited existing knowledge of the interlinkages and interactions between SDG indicators in low income and lower middle-income countries.

This article therefore uses data from seven low income and lower middle-income countries to analyze the interlinkages between SDG indicators 9.2.1 and 9.4.1, which monitors the level of industrialization and energy efficiency in manufacturing sector respectively. It is widely believed that higher level industrialization will reduce energy emission per manufacturing value added. However, the results suggest that beyond traditional knowledge, in the seven selected countries, SDG indicators 9.2.1 and 9.4.1 are positively associated with each other. A possible reason of this unconventional finding is the country context, as in low income and lower middle-income countries the manufacturing industries are usually not energy-extensive, although not technology-intensive either. This article also calls for holistic and integrated approaches to use and interpret SDG indicators in line with the national and regional context.
\end{abstract}

Keywords: SDGs, Indicators; Interlinkage, Manufacturing development, Country context

\section{Introduction}

\subsection{Background}

In the United Nations (UN) Sustainable Development Summit 2015, the 2030 Agenda for Sustainable Development (hereafter '2030 Agenda') was adopted. A core component of the 2030 Agenda is a group of 17 Sustainable Development Goals (SDGs), covering a wide range of dimensions of sustainable development such as poverty reduction, public health, food supply and environment sustainability. Since the initiation, SDGs have started to become a guidance or tool of practice and scientific research in the field of sustainable development (Biermann et al, 2017). Also, there has been an increasing academic and practical attention to the interactions between different SDGs and target and indicators under SDGs.

This article joins the discussion about the interlinkages between SDGs as well as their targets and indicators. Before moving to the research questions and methods, the articles briefly reviews the development and progress of SDGs, and also introduces some relevant literature on the interlinkage and integration of SDGs.

\subsection{Development and Progress of SDGs}

As a framework, SDGs can be considered as an extension and expansion of the eight Millennium Development Goals (MDGs) (Griggs et al., 2014; Stafford-Smith et al., 2017), which were adopted in 2000, with the aim to reduce extreme poverty by 2015 . In June 2012, member states at the United Nations Conference on Sustainable Development adopted to launch a process to develop SDGs based on MDGs. In the following year, an Open Working Group was established by the UN General Assembly to develop and draft a proposal of SDGs. This becomes a basis for the international negotiations including the UN General Assembly negotiation process of the 
post-2015 Development Agenda, which is the foundation of the adoption of the 2030 Agenda. The 17 SDGs are the core components of the 2030 Agenda.

The UN Statistical Commission is a key department in the development and progress of SDGs. In 2015, it initiated the Inter-agency and Expert Group on SDG Indicators (IAEG-SDGs), which was given the task to develop and implement an international framework of sustainable development indicators for the 2030 Agenda. IAEG-SDGs convenes two meetings each year, and establishes three working groups to respectively address three fields about developing and implementing SDGs indicators, which include the interlinkages between indicators. Participants of the $48^{\text {th }}$ session of the UN Statistical Commission in March 2017 agreed the framework of indicators developed by IAEG-SDGs, which was formally adopted by the UN General Assembly in July 2017 (UN General Assembly, 2017). The IAEG-SDGs also provides recommendations of refinements of the SDGs framework of indicators. The most updated SDGs framework of indicators was agreed upon in March 2020 in the $51^{\text {st }}$ session of UN Statistical Commission. UN Statistical Commission also oversees the work of UN Statistics Division, which undertakes the important responsibilities such as operating the Global SDG Indicators Database and managing the SDGs Knowledge Platform. More details about the development and progress of SDGs can be obtained from the SDGs Knowledge Platform and relevant official documents of UN General Assembly and IAEG-SDGs meetings.

\subsection{Interlinkages between and Integration of SDG Indicators}

Interlinkages between and integration of SDG indicators have attracted attention from scholars and practitioners. For example, Waage et al. (2015) classify the 17 SDGs into three layers: 'natural environment', 'infrastructure' and 'wellbeing', in which the delivery of 'wellbeing' goals are supported by SDGs at 'infrastructure'. Although the importance of each indicator is observed, Waage et al. (2015) also note that there is only one goal is related to health in the 17 SDGs rather than three goals related to health in eight MDGs. Griggs et al. (2014, P48) find that 'Socioeconomic development and global sustainability are often used as being in conflict because of trade-offs...', which is a key reason of developing relevant integrated models or frameworks to analyze, monitor, and evaluate different SDGs and their indicators. The emerging concept 'Water-Energy-Food Nexus' (e.g. Simpson \& Jewitt, 2019) can be considered as a typical example to integrate different SDG indicators and analyze the interactions between them (Biggs et al., 2015). Similarly, an environment-economic-health nexus is provided by Cerf (2019) to improve universal health coverage and assist to achieve SDG 3.

The practical implementation of SDGs also demonstrate trade-offs, prioritizations, and negotiations. For example, Wong \& van der Heijden (2019) find that the avoidance of conflicts may actually hamper the implementation of SDGs, as some conflicts such as those related to long-standing issues may be necessary for achieving integration. Such avoidance of conflicts is possibly because of actors have limited knowledge of the relevant targets and actions (Wong and van der Heijden, 2019), and this is also related to SDG indicators. For example, according to IAEGSDGs (2019), data for Tier 2 SDG indicators are not regularly produced by countries so that they may not be familiar to country actors, while Tier 3 SDG indicators even do not have internationally established methodology or standards (Note 1). Taking a small island country for case study, Adshead et al. (2019) emphasize the important role of infrastructure in delivering SDGs, as well as the trade-offs between indicators when making investment and policy intervention decisions. Similarly, Schroeder et al. (2019) find that although synergies that can be created through circular economy across SDGs and their targets, trade-offs exist between different SDGs and their targets, especially in the field of environment, decent work, and human health. Such trade-offs and prioritizations reflect and are also reflected by the dynamic and interdisciplinary nature of SDG indicators, as well as the complicated political process and international negotiations of sustainable development (Hák et al., 2016; Nilsson et al., 2016).

Using a holistic approach, Moldavska and Welo (2019) incorporate SDGs into corporate sustainability assessment in manufacturing firms. It also points out the research prospects of ' ....interconnections between the criteria for sustainable manufacturing and between the criteria for sustainable world' (Moldavska and Welo, 2019, p66), which demonstrates the interdependence of different SDG indicators, especially those related to manufacturing. This is also a reason for this article to analyze the interactions between two indicators of SDG 9. Furthermore, although there are some existing studies about implementation of SDGs, there is insufficient attention to the interlinkages and interdependencies among different SDGs and indicators (Stafford-Smith et al., 2017). In addition, the national and regional context of analyzing, implementing and monitoring SDGs and relevant indicators are also important (Nilsson et al., 2016). Studies on interactions of different SDGs and indicators in low income countries and lower middle-income countries are also limited due to relatively weak statistical capacity in these countries (as often measured by indicators 17.18.2 and 17.18.3). Therefore, to enrich the relevant knowledge and bridge this gap, this paper choose seven low income and lower middle-income countries to examine the interdependence and interactions of indicators 9.2.1 and 9.4.1. 


\section{Questions, Data, and Methodology}

This article examines the interlinkage between SDG indicators 9.2.1 and 9.4.1 in a few selected low income and lower middle-income countries. Both indicators are monitored by United Nations Industrial Development Organization (UNIDO), which is a UN Specialized Agency to promote industrial development for poverty reduction, inclusive globalization and environmental sustainability. SDG indicator 9.2.1 is 'Manufacturing value added (MVA) as a proportion of GDP and per capita', in which MVA per capita is reported in 2015 constant US Dollar (USD). This is a popular indicator to assess the level of industrialization of a country, as it is adjusted for the size of the economy and population. The measurement of MVA in 2015 constant USD also enables international and/or cross-year comparisons. SDG indicator 9.4.1 is ' $\mathrm{CO}_{2}$ emission per unit of value added', which calculates as ratio between $\mathrm{CO}_{2}$ emissions from fuel combustion and the value added of manufacturing sector. The unit of value added is also 2015 constant USD which is suitable for international and over-year comparisons. This is an indicator measuring the carbon intensity and energy efficiency in manufacturing sector, which can also show the technological progress of manufacturing production. Therefore, it is an indicator which monitors multidimensions of development such as environment, economy, and technology. This indicator has important role in environment protection because $\mathrm{CO}_{2}$ emission accounts for about 4/5 of all Greenhouse Gas emission from fuel combustion during the manufacturing processes (Note 2)

This article chooses the 2017 data of SDG indicators 9.2.1 and 9.4.1 for seven low income and lower middleincome countries, as defined by the World Bank (2020). These seven countries are Algeria (North Africa), Ethiopia (Sub-Sahara Africa), Haiti (Latin America and Caribbean), Pakistan (South Asia), Tajikistan (Central Asia), Ukraine (Europe), and Yemen (Middle East). These countries are selected mainly because of their relatively low socioeconomic status, for example, they are low income or lower middle-income countries, and have experienced social and/or economic turmoil in recent years. In addition, these countries are selected to have adequate geographic representativeness, as they are in major regions of the world in where a lot of developing countries are located. The 2017 data is chosen by this article because that is the most recent data for SDG indicator 9.4.1 at UNIDO Statistics Data Portal, although data for SDG indicator 9.2.1 is available up to the year 2019. All the data are publicly available via UNIDO Statistics Data Portal (2019).

In consideration of the research question, as well as the sample size and data, the article examines the interaction and interlinkage between SDG indicators 9.2.1 and 9.4.1 by calculating the correlations between them. With the assistance of SPSS, this article reports both Pearson 'r' value and Spearman 'rho' value to explore the correlations.

\section{Results and Discussion}

The descriptive data are presented in Table 1. The correlation coefficients between SDG indicators 9.2.1 and 9.4.1 are reported in Table 2. Data are from UNIDO Statistics Data Portal (2019).

Table 1. Descriptive data

\begin{tabular}{lll}
\hline Country & MVA per capita (SDG indicator 9.2.1) & $\mathbf{C O}_{2}$ emission per unit of value added (SDG indicator 9.4.1) \\
\hline Ethiopia & 51 & 0.87 \\
Haiti & 61 & 0.9 \\
Ukraine & 265 & 2.54 \\
Yemen & 84 & 0.45 \\
Tajikistan & 170 & 1.01 \\
Pakistan & 190 & 1.41 \\
Algeria & 191 & 1.04 \\
Mean (Standard Error) & $144.57(80.39)$ & $1.174(0.666)$ \\
\hline
\end{tabular}

Table 2. Correlation results

\begin{tabular}{lllll}
\hline & & & Indicator 9.2.1 & Indicator 9.4.1 \\
\hline Pearson (r) & Indicator 9.2.1 & Coefficient & 1 & 0.810 \\
& & Sig. & - & $0.027^{* *}$ \\
Spearman (rho) & Indicator 9.4.1 & Coefficient & 0.857 & 1 \\
& & Sig. & $0.014^{* *}$ & - \\
\hline
\end{tabular}


The results from Tables 1 and 2 show that in these seven countries, there is a strong positive correlation between MVA per capita and $\mathrm{CO}_{2}$ emission per unit of value added from manufacturing sector. The Pearson ' $r$ ' coefficient is 0.81 , and the Spearman 'rho' value is 0.857 , both demonstrate that the correlation between the two selected indicators is strong and positive. The significance values of both coefficients are lower than 0.05 , which show that the correlation coefficients are statistically significant.

These results contradict to the popular belief and conventional knowledge. This is because, as introduced in the metadata of the two indicators, MVA per capita (in 2015 constant USD) reflects the level of industrialization of a country including the technology intensity, and $\mathrm{CO}_{2}$ emission per unit of value added (in 2015 constant USD) is an (adverse) indicator of technology intensity and energy efficiency. Therefore, it is widely believed that the higher the MVA per capita is, the fewer $\mathrm{CO}_{2}$ is emitted for each unit of value added. However, the results in Table 2 demonstrate a different direction of correlation, which suggests that if a country's MVA per capita is higher, then its $\mathrm{CO}_{2}$ emission per unit of value added is also higher. Such unconventional findings require suitable explanations.

A possible reason of this unconventional finding is the country context. These seven countries are all low income or lower middle-income countries. Therefore, their levels of industrialization are also relatively low. This may mean that manufacturing sector in these countries may not be energy-extensive, although not technology-intensive either. To give a typical example, in countries with relatively low levels of industrialization, the dominant manufacturing industries are usually with low technology-intensity (such as production of food and beverage). Some of these low-technology intensity industries, on the other hand, do not emit large amounts of $\mathrm{CO}_{2}$ either. In contrast, countries with higher MVA per capita, although have relatively higher levels of industrialization, may also host more energy extensive industries at meantime. A typical example in this seven countries is Ukraine. It is a country which has a strong manufacturing sector (reflected by its MVA per capita, an obvious outlier of these seven countries). However, as its manufacturing is heavily inherited from the former USSR period, the military industries have a strong presence in Ukraine (e.g., Chandler, 1996), which could be an important reason of the high $\mathrm{CO}_{2}$ emission per unit of value added, as military related industries are often energy extensive and pay relatively weaker attention to environment protection.

The above analysis also leads to further thoughts about whether SDG indicators can exactly measure the issues as planned. This article provides evidence that SDG indicators may not be able to properly reflect the situations as planned in the metadata, especially if they were used in a separated approach without paying sufficient attention to the interlinkage and interaction with other SDG indicators. For example, SDG indicator 9.4.1 aims to measure the energy efficiency and the level eco-friendly production in manufacturing, but if related indicators such as SDG indicator 9.2.1 were not taken into consideration, solely reliance on SDG indicator 9.4.1 may lead to inaccurate interpretation such as 'energy efficiency in Ukraine's manufacturing sector is lower than in Yemen, because Table 1 shows that its $\mathrm{CO}_{2}$ emission per unit of value added is much higher than Yemen's manufacturing sector'.

This article finds evidence to support the argument that country and regional context should be considered when monitoring and interpret SDGs and relevant indicators (e.g. Nilsson et al, 2016). Country context may vary sharply even within the same country group (e.g. lower middle-income countries). In this article, Ukraine is an outliner although it is a lower middle-income country, which reflects that the level of industrialization and general socioeconomic development in Europe (including the former USSR countries in Europe) is higher than many other parts of the world. This may suggest that the interpretation of SDG indicators in European countries could be significantly differ from low income countries in Africa, which may have much lower level of industrialization and need longer periods for industrial upgrade.

\section{Conclusion}

This article uses data from UNIDO Statistical Data Portal to explore the interlinkage and interactions between SDG indicators 9.2.1 and 9.4.1 in seven low income and lower middle-income countries. The results show that being different from popular belief and existing knowledge, in these seven countries, the two indicators are positively and significantly correlated with each other. That means, the higher level of industrialization is likely to coexist with lower level of energy efficiency. Some explanations to this unconventional result are therefore provided.

The analysis also leads to further thoughts and discussions on the plausibility and suitability of SDG indicators. This article argues that the use of SDG indicators should take the country and regional context into consideration. Also, holistic and integrated approaches are recommended to analyze and interpret data and results of SDG indicators. For example, when interpreting the data about energy efficiency in manufacturing (SDG indicator 9.4.1), it is suggested to take the level of industrialization and manufacturing productivity (SDG indicator 9.2.1) into 
account. This article has an objective to raise the awareness of using SDGs in holistic and approaches in line with the national and regional context.

This article, as a preliminary practice-oriented research note, is not without limitations, which leaves spaces for future research. Due to the limited sample size, more sophisticated statistical methods are not used in this article. Future studies may be able to expand the sample size and use more sophisticated statistical analysis. Moreover, although the countries selected have experienced social and economic turmoil in recent years, this article has not further discussed whether and how such turmoil may affect the industrialization and manufacturing development in these countries, and whether and how the interaction and interlinkage between SDG indicators are affected by social and economic turmoil in these countries. For example, future research may investigate how the recent domestic military conflicts in Ukraine and Yemen affect the industrialization and energy efficiency improvement in these two countries. This article has an aim to raise the awareness of the interlinkage between SDG indicators and inspire discussions on the impact of country context on SDGs and relevant indicators.

In addition, comparisons of interaction and interlinkage between SDG indicators across countries and country groups (such as among low income, lower middle-income, upper middle-income, and high income countries; or among Sub-Sahara African, Central Asia, and Latin American and Caribbean countries) could also generate interesting findings. This article lays out a foundation for the author and other researchers to conduct such comparative studies in the future. Intra-group disparities also deserve sufficient attention when exploring the interlinkage between SDG indicators.

\section{Acknowledgement}

The author would like to express sincere appreciation to insights from former peers and colleagues at University of Oxford, Imperial College London, and United Nations Industrial Development Organization (UNIDO). Unless otherwise specified, the views expressed in this article are the author's and do not represent any official stance of academic institutes and/or United Nations (UN) as well as its subordinate departments and agencies including UNIDO. This article is an independent research output and receives no support from any government, business organizations, non-governmental organizations, and UN departments and agencies. Therefore the author declares no conflict of interest.

\section{References}

Adshead, D., Thacker, S., Fuldauer, L. I., \& Hall, J. W. (2019). Delivering on the Sustainable Development Goals through long-term infrastructure planning. Global Environmental Change, 59(August), 101975. https://doi.org/10.1016/j.gloenvcha.2019.101975

Biermann, F., Kanie, N., \& Kim, R. E. (2017). Global governance by goal-setting: the novel approach of the UN Sustainable Development Goals. Current Opinion in Environmental Sustainability, 26-27, 26-31. https://doi.org/10.1016/j.cosust.2017.01.010

Biggs, E. M., Bruce, E., Boruff, B., Duncan, J. M. A., Horsley, J., Pauli, N., ... Imanari, Y. (2015). Sustainable development and the water-energy-food nexus: A perspective on livelihoods. Environmental Science and Policy, 54 (December), 389-397. https://doi.org/10.1016/j.envsci.2015.08.002

Cerf, M. E. (2019). Sustainable Development Goal Integration, Interdependence, and Implementation: the Environment-Economic-Health Nexus and Universal Health Coverage. Global Challenges, 3(9), 1900021. https://doi.org/10.1002/gch2.201900021

Chandler, A. (1996). Statebuilding and Political Priorities in Post-Soviet Ukraine: The Role of the Military. Armed Forces \& Society, 22(4), 573-597. https://doi.org/10.1177/0095327X9602200405

Griggs, D., Smith, M. S., Rockström, J., Öhman, M. C., Gaffney, O., Glaser, G., ... Shyamsundar, P. (2014). An integrated framework for sustainable development goals. Ecology and Society, 19(4). http://dx.doi.org/10.5751/ES-07082-190449

Hák, T., Janoušková, S., \& Moldan, B. (2016). Sustainable Development Goals: A need for relevant indicators. Ecological Indicators, 60 (January), 565-573. https://doi.org/10.1016/j.ecolind.2015.08.003

IAEG-SDGs (2019). Tier Classification for Global SDG Indicators. Retrieved May 29, 2020, from https://unstats.un.org/sdgs/iaeg-sdgs/tier-classification/

Moldavska, A., \& Welo, T. (2019). A Holistic approach to corporate sustainability assessment: Incorporating sustainable development goals into sustainable manufacturing performance evaluation. Journal of Manufacturing Systems, 50(January), 53-68. https://doi.org/10.1016/j.jmsy.2018.11.004 
Nilsson, M., Griggs, D., \& Visbeck, M. (2016). Policy: Map the interactions between Sustainable Development Goals. Nature, 534(7607), 320-322. https://doi:10.1038/534320a

Schroeder, P., Anggraeni, K., \& Weber, U. (2019). The Relevance of Circular Economy Practices to the Sustainable Development Goals. Journal of Industrial Ecology, 23(1), 77-95. https://doi.org/10.1111/jiec.12732

Simpson, G. B., \& Jewitt, G. P. W. (2019). The development of the water-energy-food nexus as a framework for achieving resource security: A review. Frontiers in Environmental Science, 7(February), 1-9. https://doi.org/10.3389/fenvs.2019.00008

Stafford-Smith, M., Griggs, D., Gaffney, O., Ullah, F., Reyers, B., Kanie, N., ... O’Connell, D. (2017). Integration: the key to implementing the Sustainable Development Goals. Sustainability Science, 12(6), 911-919. https://doi.org/10.1007/s11625-016-0383-3

UN General Assembly (2017). Resolution adopted by the General Assembly on 6 July 2017. A/RES/71/313.

UNIDO Statistics Data Portal (2019) SDG 9 database. Retrieved May 29, 2020, from https://stat.unido.org/SDG

Waage, J., Yap, C., Bell, S., Levy, C., Mace, G., Pegram, T., ... Poole, N. (2015). Governing the UN sustainable development goals: Interactions, infrastructures, and institutions. The Lancet Global Health, 3(5), e251-e252. https://doi.org/10.1016/S2214-109X(15)70112-9

Wong, R., \& van der Heijden, J. (2019). Avoidance of conflicts and trade-offs: A challenge for the policy integration of the United Nations Sustainable Development Goals. Sustainable Development, 27(5), 838-845. https://doi.org/10.1002/sd.1944

World Bank. (2020). World Bank Country and Lending Groups. https://datahelpdesk.worldbank.org/knowledgebase/articles/906519-world-bank-country-and-lendinggroups\#: :text=For\%20the\%20current\%202020\%20fiscal,those\%20with\%20a \%20GNI\%20per accessed on 16 June 2016.

\section{Notes}

Note 1. SDG indicators are classified into three tiers (Tier 1, Tier 2, and Tier 3) according to the availability and clearness of definitions, methods, standards, data collection and reporting. Due to a lack of clear standards or methods, there is no Tier 3 indicator included in the SDG framework as of the 51st session of the UN Statistical Commission. For more details, see the IAEG-SDGs website of tier classification https://unstats.un.org/sdgs/iaegsdgs/tier-classification/ (accessed on 29 May 2020).

Note 2. Figure from UNIDO Statistics Data Portal on SDGs https://stat.unido.org/SDG, accessed on 29 May 2020. More details of SDG 9 indicators and relevant metadata can also be found on this website.

\section{Copyrights}

Copyright for this article is retained by the author(s), with first publication rights granted to the journal.

This is an open-access article distributed under the terms and conditions of the Creative Commons Attribution license (http://creativecommons.org/licenses/by/4.0/). 